\title{
A Páscoa e o Natal: a comemoração dentro da escola
}

\section{Easter and Christmas: the celebration in school}

Denise Mak possui graduação em Pedagogia pela Universidade Presbiteriana Mackenzie. Atualmente é professora de educação infantil pela Prefeitura Municipal de São Paulo. Faz parte do grupo de pesquisa sobre Educação, História e Religião (GEHER). Mestranda em Educação: História, Política, Sociedade (PUC-SP).

\section{Contato: denimk20@hotmail.com}

\section{Resumo}

Este trabalho tem como objetivo traçar um paralelo entre cultura escolar e memória, tendo como eixo norteador duas datas religiosas, Páscoa e Natal, celebradas anualmente dentro do âmbito escolar. Para tanto, o conceito de memória apresentado por Le Goff (2003) será fundamental para discutir como a religião cristã é tida como uma religião da recordação, sendo que contribui inevitavelmente para uma cultura escolar que, conforme Julia (2001), deve ser pensada conjuntamente com outras culturas, dentre elas a religiosa. A análise será feita especificamente com escolas de Educação Infantil, pois as datas mencionadas são constantemente trabalhadas nelas, possibilitando uma reflexão sobre o tema. Palavras-chave: cultura escolar; religião; memória; educação infantil.

\section{Abstract}

This paper aims to draw a parallel between school culture and memory, specifically in two religious dates, Easter and Christmas, celebrated annualy in the school context. To do so, Le Goff's (2003) concept of memory will be essencial to discuss how Christian religion is seen as a religion of remembrance, that contributes inevitably to a school culture that, according to Julia (2001), should be considered in 
conjunction with other cultures, among them the religious one. The analysis will be done specifically in kindergarten schools, given that the aforementioned dates are constantly worked on them.

Keywords: school culture; religion; memory; kindergarten.

\section{Introdução}

A história da educação brasileira demonstra que desde seu início houve uma forte presença do cristianismo, inicialmente com a tentativa de impor aos nativos a religião cristã e uma cultura eurocêntrica. Esse objetivo se estendeu por todo o percurso educacional brasileiro.

0 período republicano, que em seu princípio era defensor da escola pública laica, cedeu a pressões de uma forte corrente católica e acabou por instituir em sua segunda Constituição, e nas outras que surgiriam, o Ensino Religioso. Atualmente, após vários debates, tem-se a LDB 9.394/96 que, em seu artigo 33, prevê:

\footnotetext{
O ensino religioso, de matrícula facultativa, é integrante da formação básica do cidadão e constitui disciplina dos horários normais das escolas públicas de ensino fundamental, assegurado o respeito à diversidade cultural religiosa do Brasil, vedadas quaisquer formas de proselitismo (BRASIL, 1997).
}

Esse artigo deixa claro que as escolas de ensino fundamental devem ofertar o Ensino Religioso, mas como a religião entraria especificamente na escola pública de educação infantil? As datas comemorativas proporcionam um viés para encontrar alguns indícios sobre o tema aqui proposto - memória/religião/escola -, pois demonstram que não houve a efetivação de um país laico. Trazer esse debate à tona é o intento deste trabalho.

\section{Educação Infantil, memória e cultura escolar}

A cultura estabelecida dentro de muitas escolas, mais especificamente as que atendem crianças na faixa etária de 0 a 6 anos - Creches e Escolas de Educação Infantil - não desconsideram e sempre debatem sobre como comemorar datas especiais, como é o caso da Páscoa e do Natal. 
Obviamente, outras datas específicas ligadas a uma lógica de consumo na sociedade brasileira contemporânea também constam na pauta dessas escolas - como o Dia das Mães, Dia dos Pais, Dia das Crianças, entre outras - mas aquelas chamam a atenção por se tratarem de festas religiosas e que foram incorporadas ao calendário escolar, tidas por muitos educadores como uma cultura constitutiva da sociedade.

Nas escolas, tanto aquelas nas quais já trabalhei quanto a escola na qual realizo minha pesquisa atualmente - que trata sobre como os agentes escolares trazem para dentro do seu campo profissional suas manifestações religiosas -, as datas mencionadas podem ser comparadas a ritos de inculcação. Hobsbawm analisa as tradições nas sociedades como algo inventado. Ele as define como "[...] realmente inventadas, construídas e formalmente institucionalizadas, quanto as que surgiram de maneira mais difícil de localizar num período de tempo - às vezes coisa de poucos anos apenas - e se estabeleceram com enorme rapidez" (1984, p. 9). Pode-se considerar que festas religiosas como a Páscoa e o Natal assumiram um papel institucionalizado dentro do âmbito escolar, o que as torna algo pouco problematizado, quase naturalizado, trabalhado muitas vezes por uma perspectiva inocente de educação.

Nos dias atuais, há discussões pontuais em reuniões pedagógicas sobre o tema aqui proposto, principalmente em épocas do ano que envolvam as datas comemorativas; isto pode ser verificado na pesquisa de campo em andamento e no percurso profissional vivenciado. Alguns educadores se posicionam favoráveis à incorporação dessas datas no calendário escolar; uma minoria enfatiza o consumismo de tais comemorações, além de argumentarem que são mal trabalhadas dentro de sala de aula pois, no caso da Educação Infantil, trabalham-se constantemente tarefas como: fazer orelhas de coelho, presentear com ovo ou colocar algodão na barba do Papai Noel. São tradições sociais adaptadas/incorporadas pela escola, institucionalizadas.

Nesse caso, ao pensarmos nas comemorações e em sua apropriação feita por parte dos sujeitos pertencentes ao espaço escolar, Hobsbawm (1984) traz uma importante contribuição ao definir que: 
Essa "tradição" e sua naturalização nos meios sociais pode ser vinculada ao conceito de memória, apresentado por Le Goff (2003), e com o conceito de cultura escolar, pois ambos podem ser analisados em uma perspectiva histórica e condizem com a vida social, além de serem um objeto de manipulação do Estado, o que permite uma reflexão sobre como a religião está presente dentro da Educação Infantil.

O Estado legitima uma história oficial e inquestionável; como forma de controle, a educação é um meio pelo qual o Estado pode agir, principalmente sabendo que "A noção de aprendizagem, importante na fase da aquisição da memória, desperta o interesse pelos diversos sistemas de educação da memória que existiram nas várias sociedades e em diferentes épocas: as mnemotécnicas." (Idem, p. 420).

A memória, segundo Le Goff (2003), possui uma relação direta com a vida social, indo além do individual, e adquire significado em determinados grupos sociais. Para esse autor, a memória possui uma historicidade, pois pode ser constatada em documentos e monumentos. Além disso, ele averigua que "com a passagem da oralidade à escrita, a memória coletiva e, mais particularmente, a 'memória artificial' são profundamente transformadas" ( $p$. 430). 0 autor exemplifica as sociedades ágrafas a partir de seus especialistas em memórias, que sempre narravam acontecimentos memoráveis. Entretanto, a recontagem desses acontecimentos poderia trazer modificações por quem os contava; assim, o aparecimento da escrita é um importante episódio para a memória, pois segundo o autor:

A escrita permite à memória coletiva um duplo progiresso, o desenvolvimento
de duas formas de memória. A primeira é a comemoração, a celebração
através de um monumento comemorativo de um acontecimento memoriável.
(p. 427)

É importante discutir o conceito de memória e como ele assume diversas perspectivas. Primeiramente: 
Conforme a citação acima, a memória possui um movimento próprio e se faz a partir do presente. Além disso, a memória "ganhou ar de moda historiográfica servindo a usos institucionais, investidas patrimoniais e comemorações oficiais e, também, a resistências e afirmações (muitas vezes, inusitadas) de direitos e cidadanias..." (Idem, p. 44). Verifica-se, ao se fazer um paralelo com a escola, que a memória é utilizada como cultura escolar para a sua constituição institucional, pois o artigo 33 da LDB responde a uma demanda social para a afirmação da memória religiosa como direito. Além disso, na Educação Infantil as comemorações têm como alvo a memória coletiva por fazer sentido perante um grupo. Nesse caso, somente os cristãos são contemplados, pois se verifica que há uma negação de outros grupos religiosos, por parte dos educadores, principalmente na Educação Infantil. Outras religiões ou a ausência de crença não são comumente abordadas nessa etapa do ensino.

0 predomínio de determinadas religiões na escola pode, sim, ser uma forma de manipulação e uma intenção clara de determinada ideologia impor uma cultura homogeneizada para determinada classe social. Para Julia (2001),

\footnotetext{
[...] cultura escolar não pode ser estudada sem a análise precisa das relações conflituosas ou pacíficas que ela mantém, a cada período de sua história, com o conjunto das culturas que lhe são contemporâneas: cultura religiosa, cultura política ou cultura popular. Para ser breve, poder-se-ia descrever a cultura escolar como um conjunto de normas que definem conhecimentos e condutas a inculcar, e um conjunto de práticas que permitem a transmissão desses conhecimentos e a incorporação desses comportamentos; normas; e práticas coordenadas a finalidades que podem variar segundo as épocas (finalidades religiosas, sociopolíticas ou simplesmente de socialização) (p. 10).
}

Julia (2001) traz uma reflexão importante quando trata de condutas a inculcar. A religião pode fazer parte desse processo, principalmente quando educadores adotam certas práticas moralizantes abarcadas por ela, lembrando que a cultura escolar sempre está em constante mudança, por seu aspecto histórico. A memória tem uma relação direta com a vida, indo além do individual e encontrando significado no grupo social, segundo Le Goff (2003).

Para entender como a cultura escolar ajuda a construir a memória social, Frago (2006) traz uma contribuição importante, ao afirmar que 
A cultura escolar, assim entendida, estaria constituída por um conjunto de teorias, ideias, princípios, normas, orientações, rituais, inércias, hábitos e práticas (formas de fazer e pensar, mentalidades e comportamentos) sedimentadas ao longo do tempo sob forma de tradições, regularidades e regras de jogo não questionadas e compartilhadas pelos seus atores dentro das instituições educacionais. Tradições, regularidades e regras de jogo que se transmitem de geração a geração e que proporcionam estratégias [...]. (p.73, tradução nossa)

A cultura escolar, assim como a memória, é passada de geração a geração e possui uma estratégia objetivada. Verificase que a memória, por possuir uma historicidade, sempre foi um instrumento, um objeto de quem constitui o poder; tal premissa pode estar diretamente ligada ao objetivo de colocar dentro da escola determinados preceitos que interessam a um poder manipulador, algo que deveria ser questionado pela comunidade escolar. A religião seria um modo de atingir esse intento. Além disso,
(...) na medida em que há referência a um passado histórico, as tradições "inventadas" caracterizam-se por estabelecer com ele uma continuidade bastante artificial. Em poucas palavras, elas são reações a situações novas que ou assumem a forma de referência a situações anteriores, ou estabelecem seu próprio passado através da repetição quase que obrigatória (HOBSBAWM, 1984, p.10).

Assim, a escola assume uma tarefa artificial de reagir às novas situações para englobar dentro de sua proposta curricular a Páscoa e o Natal, além de outras datas comemorativas.

\section{Cenas da pesquisa - algumas considerações acerca de pesquisa realizada em uma EMEI}

Dentro deste tópico pretende-se analisar três cenas da pesquisa realizada em uma EMEI na zona leste de São Paulo, no distrito de Itaim Paulista, tendo como aporte teórico autores que discutem a questão da memória e da cultura escolar.

Duas cenas ocorreram na reunião pedagógica, primeiro contato com a escola, no dia em que o projeto foi apresentado ao grupo de educadores sujeitos da pesquisa. Nessa ocasião eles tiveram a oportunidade de questionar o que foi exposto. A outra cena diz respeito à fala de uma professora. 


\section{Cena 1 - Reunião Pedagógica.}

Uma professora se posiciona em relação ao calendário escolar, que engloba, inevitavelmente, datas religiosas:

Como não trabalhar a religião, pois a Páscoa, por exemplo, faz parte do calendário escolar, o calendário já coloca as datas religiosas.

Explico que:

Justamente isso que quero saber, pois, se o calendário engloba as datas, quero saber como elas (as professoras) trabalham essa temática em sala.

Segundo Julia (2001) a escola é um lugar de "inculcação de comportamentos e de habitus". No caso de trabalhar com a data, esta pode, sim, ser uma resposta ao sujeito que a escola pode formar.

Quanto à questão da memória, há aqui um forte traço de que há uma influência religiosa cristã dentro da escola para comemorar, ou lembrar conjuntamente, a morte e ressurreição de Cristo. Por mais que nos dias atuais o sentido religioso esteja banalizado, a Páscoa é uma data indiscutivelmente religiosa e tem sido um instrumento de manipulação utilizado pelo Estado, Igreja, enfim por uma ideologia dominante, por se tratar da imposição de uma determinada cultura religiosa para uma diversidade escolar. 0 discurso dessa professora pode levar ao que Le Goff (2003, p.422) enuncia quanto às "manipulações conscientes e inconscientes que o interesse, a afetividade, o desejo, a inibição, a censura exercem sobre a memória individual".

Dessa forma, a manipulação da memória se faz necessária para a inculcação de certos saberes nos agentes que compõem a escola.

\section{Cena 2 - Reunião Pedagógica. 01/03}

A questão da Páscoa foi abordada pela coordenadora, durante a reunião, com a seguinte fala:

Ano passado fizemos a partilha de pão, mas o grupo tem repensando a data e decidiu que isso tem um viés religioso, sendo assim, optou-se pela pesquisa com os pais, sem que haja presentes para as crianças. 
É interessante como a escola ainda trabalha a Páscoa dentro do seu espaço: no ano de 2012, segundo a fala da coordenadora, o trabalho realizado para a comemoração da data foi a partilha de pão, enquanto que neste ano foi projetado um painel com o significado da Páscoa para a comunidade escolar¹. Miranda (2007) traz uma importante reflexão sobre o assunto, ao estabelecer que

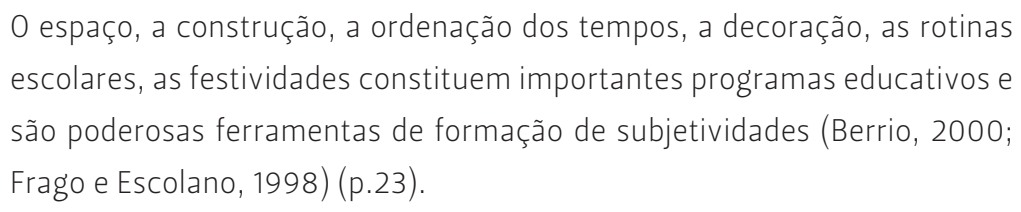

Verifica-se que há uma importância grande dada às datas comemorativas. Nesse caso, tem-se uma cultura escolar na qual a Páscoa é uma prática que possui uma finalidade e que pode ser vista como uma expressão da cultura escolar da unidade pesquisada.

\section{Cena 3 - Conversa com uma professora.}

Enquanto as crianças desenhavam, fiz alguns questionamentos à professora:

$P$ : Você tem alguma religião?

R: Sim, eu sou Hare Krishna.

$P$ : Você acha que há uma influência cristã dentro da escola?

$R$ : Sim, tem muita professora que diz que não, mas já vi algumas passando vídeo do nascimento de Cristo no Natal, ou como no começo do ano que passaram "Smilinguido, a moda amarela". Isso incomoda um pouco.

Passar um filme sobre o nascimento de Cristo pode ser algo comparado à questão da memória, por se tratar de pontuar algo dentro da religião cristã.

\begin{abstract}
Se a memória antiga foi fortemente penetrada pela religião, o judaicocristianismo acrescenta algo de diverso à relação entre memória e religião, entre o homem e Deus [cf. Meier, 1975]. Pôde-se descrever o judaísmo e o cristianismo, religiões radicadas histórica e teologicamente na história, como "religiões da recordação" [cf. Oexle, 1976, p.80] (LE GOFF, 2003, p. 443).
\end{abstract}

0 que as professoras fazem ao utilizar esses recursos midiáticos é inovar na forma de inculcação de saberes, pois quando se trata de educação, sabe-se que ela
1. Conferir ANEXO A: Figuras 1, 2 e 3 com fotos do painel feito pelas educadoras com as respostas da comunidade escolar. 
[...] implica um processo de inserção do indivíduo na cultura e de perpetuação dessa mesma cultura o que, diante da relação contínua com o novo, não se dá sem transformações, apesar de pressupor uma relação contínua com o passado que engendrou a cultura posta (MIRANDA, 2007, p.40).

\section{Considerações Finais}

Poucos educadores contemplam, em seus planejamentos, perspectivas mais críticas, trazendo questionamentos sobre como a religião adentrou a escola e sobre como ela inovou o aspecto cultural, tornando-se algo ligado, principalmente, ao consumismo infantil e à imposição de valores. Essas datas deveriam ser mais discutidas, para que se tenha um pensamento reflexivo sobre ao assunto. Ao se pensar na ligação entre escola e memória, pode-se afirmar que

\footnotetext{
Esta reflexão sobre os tempos da memória leva-nos à necessidade de considerar mais atentamente o fato de que eles remetem imediatamente à dimensão espacial: ou seja, os tempos da memória designam ao mesmo tempo lugares de memória, (grifo do autor) toda memória (individual ou social, coletiva) vale-se de lugares (concretos e/ou simbólicos) para se exprimir, materializa-se (SEIXAS, 2002, p. 60).
}

Assim, percebe-se que há nas escolas questões mais vinculadas à religião cristã e ao aspecto da comemoração. Como na citação acima, na escola as datas encontraram tanto um lugar concreto quanto um simbólico para serem trabalhadas, principalmente uma memória coletiva. A autora ainda diz que

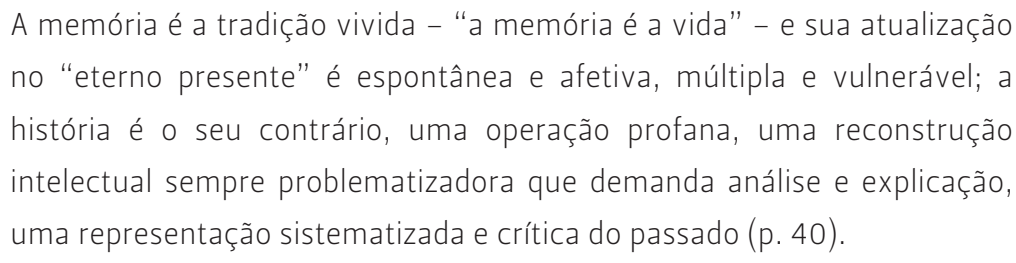

0 ambiente escolar é único, digno de uma diversidade cultural rica, que é ainda mal trabalhada e estudada. É preciso trazer essa diversidade para melhor desenvolvê-la em sala de aula, incluindo no debate feito entre educadores e educandos o saber sobre outras realidades, visões de mundo ou filosofias de vida. A maioria dos professores repete práticas sem nenhum senso crítico; o cristianismo é algo tão enraizado, tão sedimentado, que passa despercebido e naturalizado. 
Enfim, a religião é algo que está presente em nossa sociedade. Negá-la dentro da escola não é o caminho, mas saber debater com os educandos que existem pessoas que creem em outro deus ou deuses, além de pontuar quem são os ateus e os agnósticos (pois muitas vezes esses são condenados por aqueles que possuem alguma religião), para que as crianças possam escolher os próprios conceitos que querem abarcar para sua vida e, ainda, saber respeitar a diversidade religiosa existente no contexto brasileiro. Este é o viés que a escola deveria ter como embasamento para os trabalhos desenvolvidos sobre esta temática.

\section{REFERÊNCIAS}

BRASIL, Lei nº 9.475 de 20 de julho de 1997. Dá nova redação ao art. 33 da Lei ${ }^{\circ}$ 9.394, de 20 de dezembro de 1996, que estabelece as diretrizes e bases da educação nacional. Disponível em: < http://www.planalto.gov.br/ccivil_03/Leis/ 19475.htm> acesso em: 24 out. 2013.

FRAGO, Antonio Vinão. Sistemas educativos, culturas y reformas. $2^{a}$ edição. Madrid: Morata, 2006.

HOBSBAWM, Eric A Invenção das tradições. São Paulo: Paz e Terra, 1984.

JULIA, Dominique. A cultura escolar como Objeto Histórico. Revista Brasileira de História da Educação, n.1, jan./jun., p.9-43, 2001.

LE GOFF, Jacques. Memória. In: História e Memória, $5^{\text {a ed. }}$ Campinas, SP: Editora da UNICAMP, p. 419-476, 2003.

MIRANDA, Sônia. Cultura Escolar, saberes docentes e História Ensinada. São Paulo: Editora UNESP; Juiz de Fora: EDUFJF, 2007.

SEIXAS, Jacy Alves de. Os tempos da memória (des)continuidade e projeção. Uma reflexão (in)atual para a História? In: Projeto História, São Paulo. jun. p.43-63, 2002.

Recebido em: 13/07/2013 


\section{Anexo A}

Figura 1 - Parte do painel sobre a Páscoa

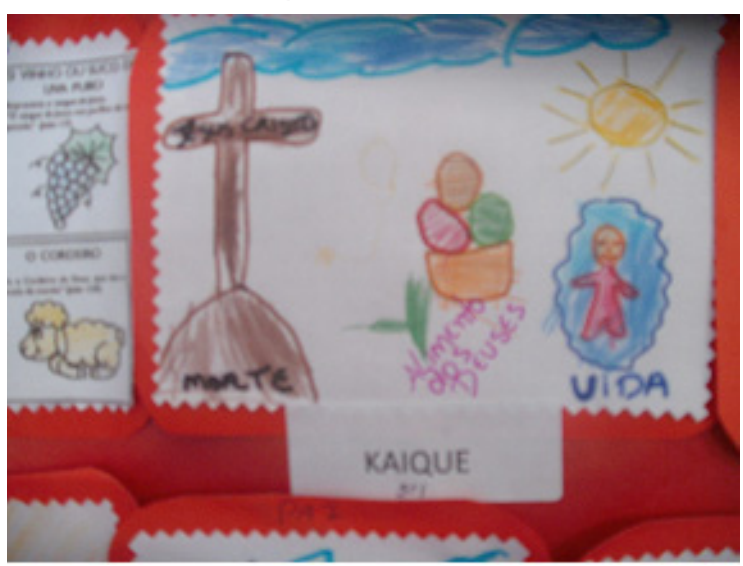

Foto: foto da autora

Figura 2. Parte do painel sobre a Páscoa

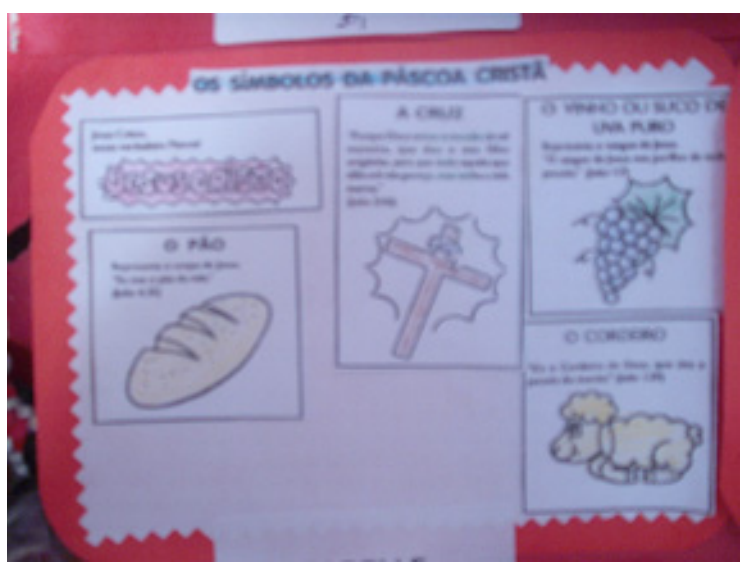

Foto: foto da autora

Figura 3. Parte do painel sobre a Páscoa

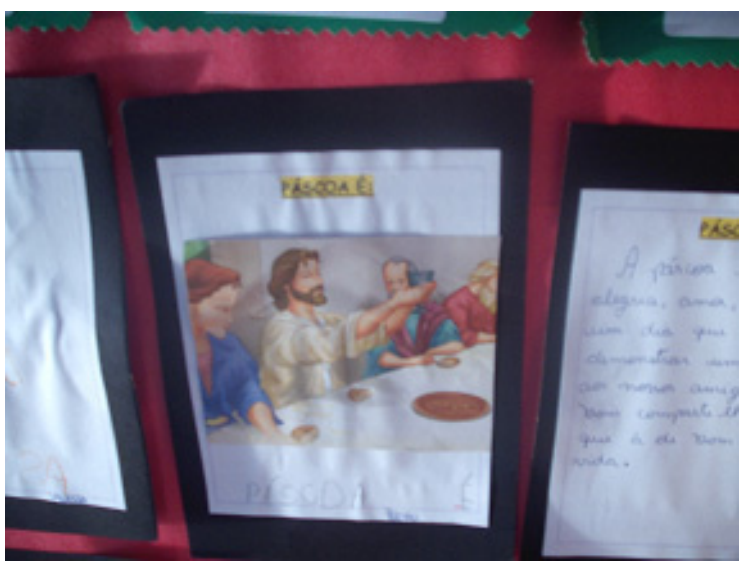

Foto: foto da autora

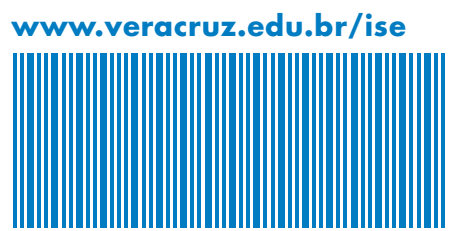

